\title{
Physiological and Functional Evaluation of the Transposed Human Pylorus as a Distal Sphincter
}

\author{
Abhijit Chandra, ${ }^{1 *}$ Uday C Ghoshal, ${ }^{2}$ Vishal Gupta, ${ }^{1}$ Ramendra Jauhari, ${ }^{3}$ Rajendra N Srivastava, ${ }^{4}$ Asha Misra, ${ }^{2}$ Ashok Kumar \\ and Manoj Kumar ${ }^{5}$ \\ ${ }^{1}$ Department of Surgical Gastroenterology, CSM Medical University, Lucknow, India; '2 Department of Gastroenterology, Sanjay Gandhi Post \\ Graduate Institute of Medical Sciences, Lucknow, India; ${ }^{3}$ Department of Surgery, SN Medical College, Agra, India; and Departments of \\ ${ }^{4}$ Orthopedic Surgery and ${ }^{5}$ Radiology, CSM Medical University, Lucknow, India
}

\begin{abstract}
Background/Aims
Studies evaluating the human pylorus as a sphincter are scanty and contradictory. Recently, we have shown technical feasibility of transposing the human pylorus for end-stage fecal incontinence. This unique cohort of patients provided us an opportunity to study the sphincter properties of the pylorus in its ectopic position.
\end{abstract}

\section{Methods}

Antro-pylorus transposition on end sigmoid colostomies $(n=3)$ and in the perineum $(n=15)$ was performed for various indications. Antro-pylorus was assessed functionally (digital examination, high resolution spatiotemporal manometry, barium retention studies and colonoscopy) and by imaging (doppler ultrasound, MRI and CT angiography) in its ectopic position.

\section{Results}

The median resting pressure of pylorus on colostomy was $30 \mathrm{mmHg}$ (range 28-38). In benign group, median resting pressure in perineum was $12.5 \mathrm{mmHg}$ (range 6-44) that increased to $21.5 \mathrm{mmHg}$ (range 12-29) $(P=0.481)$ and $31 \mathrm{mmHg}$ (range 16-77) $(P=0.034)$ on first and second follow-up, respectively. In malignant group, median post-operative pressures were 20 $\mathrm{mmHg}$ (range 14-36) and $21 \mathrm{mmHg}$ (range 18-44) on first and second follow-up, respectively. A definite tone and gripping sensation were felt in all the patients on digital examination. On distal loopogram, performed through the diverting colostomies, barium was retained proximal to the neo-pyloric valve. Both perineal ultrasound and MRI showed viable transposed graft. CT angiography and color doppler studies confirmed vascular flow in the transposed position.

\section{Conclusions}

The human pyloric valve can function as a tonic sphincter when removed from the gastroduodenal continuity.

(J Neurogastroenterol Motil 2012;18:269-277)

\section{Key Words}

Fecal incontinence; Gastroepiploic artery; Manometry; Pylorus

Received: February 16, 2012 Revised: May 14, 2012 Accepted: May 25, 2012

(c) This is an Open Access article distributed under the terms of the Creative Commons Attribution Non-Commercial License (http://creativecommons. org/licenses/by-nc/3.0) which permits unrestricted non-commercial use, distribution, and reproduction in any medium, provided the original work is properly cited.

*Correspondence: Abhijit Chandra, MS, MCh Department of Surgical Gastroenterology, CSM Medical University, Lucknow 226007, UP, India Tel: +91-522-225-8660, Fax: +91-522-225-6116, E-mail: abhijitchandra@hotmail.com

Financial support: This study was supported by Department of Surgical Gastroenterology, CSM Medical University, Lucknow (grant number 2835/ Lekha/09).

Conflicts of interest: None. 


\section{Introduction}

The pylorus is situated at the junction of two functionally distinct parts of the gastrointestinal tract. Anatomically, it can be identified as an area of thickened circular muscle. Its gross appearance suggests that it may indeed be a true sphincter. Physiologically, the pylorus is an important component of the mechanism that regulates gastric emptying and prevents duodenogastric reflux. However, conflicting claims have been made regarding the physiological characteristics of the pyloric sphincter. Unlike the upper esophageal sphincter and the anal sphincter, which are manometrically demonstrable high pressure zones, reports regarding the existence of tonic pressure in the pylorus remain contradictory. ${ }^{1,2}$ For this reason, the pylorus has also been referred to as 'fickle pylorus'.

Fecal incontinence is seen in $6.4 \%$ of the Korean population, ${ }^{4}$ and various treatment options are available with varying results. Prevalence of fecal incontinence in India is not known though it is expected to be high at least among female due to obstetric injury. We have previously demonstrated the technical feasibility of human pylorus transposition in the perineum for end- stage anal incontinence. ${ }^{5}$ This unique cohort provided us the rare opportunity to study the sphincter properties of the pylorus in its ectopically transposed position. In the present study, we evaluated the pylorus in its ectopic position by manometry and imaging to determine its tonic characteristics.

\section{Materials and Methods}

The study was approved by the Institutional Review Board (IRB, also the Ethics committee) of CSM Medical University, Lucknow, India. We considered very carefully the risk benefit equation in devising a safe surgical strategy. Subjects were fully informed about the potential advantages or complications of the procedure after a detailed discussion. Only those who expressed willingness to participate were recruited as mentioned below. This surgery was reserved for patients with end stage fecal incontinence where other options have failed resulting in an incapacitating disability, and patients being left with no choice other than having a permanent colostomy. Each patient signed a written informed consent in accordance with IRB guidelines. There were 2 children (Table) whose parents were fully informed and their collective consent was obtained.

Patient selection was based on strict inclusion and exclusion criteria. Patients included were those with a surgically excised anal sphincter (post-abdomino-perineal resection), congenitally absent anal sphincter, and traumatized anal sphincter (where conventional local repair procedures were not possible or had failed) with end stage fecal incontinence resulting in permanent colostomy. Exclusion criteria included patients where previous gastro-duodenal surgery, other abdominal surgeries with extensive adhesions, obese patient with extensive visceral fat, and patients otherwise eligible for local repair of the damaged anal sphincter.

\section{Surgical Technique}

The technique of the antro-pyloric valve (APV) transposition in humans has been described in detail in our previous paper. ${ }^{5}$ In short, APV containing the cuff of first part of the duodenum and antrum was mobilized along with the vascular arcade of the right and left gastroepiploic vessels by dividing their branches to the stomach along its greater curvature. Vascularity of this mobilized sphincter primarily depends on the left gastroepiploic artery. Gastrointestinal continuity was restored by either gastroduodenostomy or gastrojejunostomy.

Initially, to establish feasibility of this procedure, the APV was transposed on to the preexisting end-sigmoid colostomy in three patients. Subsequently, the APV was transposed in the perineum in 15 patients for various indications (Table). In all these patients, a proximal diverting colostomy was retained or re-constructed to allow the neo-sphincter to heal in anal position. The colostomy was subsequently closed after 6 weeks.

\section{Functional Evaluation \\ Digital examination}

The pylorus was assessed in its new position by digital examination by two independent observers (Fig.1 and 2).

\section{High-resolution spatio-temporal manometry}

Manometric studies were performed pre-operatively in patients with anal sphincter damage and after APV transposition on a high resolution, water perfusion spatiotemporal manometry system (G Hebberd, The Royal Melbourne Hospital, Melbourne, Australia) using standard technique and 16 port catheter. ${ }^{6,7}$ Manometry was performed without any sedation in supine position (when APV was transposed at colostomy end) or in left lateral position in other patients. Manometry catheter was gradually inserted deep in the rectum or colon through the colostomy or through the anal verge, and was pulled till the high pressure zone of sphincter was reached. The basal pressure was obtained over 1-2 minutes. The signal was analyzed using Trace $1.2 \mathrm{~V}$ software 
Table. Demographic Parameters and Results of Pyloric Valve Transposition

\begin{tabular}{|c|c|c|c|c|c|c|c|c|c|c|c|c|c|}
\hline \multirow[t]{2}{*}{ No. } & \multirow{2}{*}{ Age/Sex } & \multirow{2}{*}{ Diagnosis } & \multirow{2}{*}{ History of surgery } & \multicolumn{2}{|c|}{$\begin{array}{c}\text { Incontinence } \\
\text { score }\end{array}$} & \multicolumn{3}{|c|}{$\begin{array}{l}\text { Anal resting pressure } \\
\qquad(\mathrm{mmHg})\end{array}$} & \multicolumn{2}{|c|}{$\begin{array}{l}\text { Doppler } \\
\text { velocity } \\
(\mathrm{cm} / \mathrm{sec})\end{array}$} & \multirow{2}{*}{$\begin{array}{c}\text { Gripping } \\
\text { sensation on } \\
\quad \text { digital } \\
\text { examination }\end{array}$} & \multirow{2}{*}{$\begin{array}{l}\text { Retention of } \\
\text { barium } \\
\text { proximal to } \\
\text { APV }\end{array}$} & \multirow{2}{*}{$\begin{array}{l}\text { Pedicle of } \\
\text { gastroepiploic } \\
\text { artery till } \\
\text { transposed } \\
\text { pylorus on CT } \\
\text { angiography }\end{array}$} \\
\hline & & & & Preop & ?ostop & Preop & $\begin{array}{l}1 \mathrm{st} \\
\mathrm{F} / \mathrm{U}\end{array}$ & $\begin{array}{l}\text { 2nd } \\
F / U\end{array}$ & Max & Min & & & \\
\hline 1 & $25 / \mathrm{M}$ & High ARM & $\begin{array}{l}\text { Failed previous } \\
\text { anal pull through } \\
\text { operation } 1 \text { year } \\
\text { back }\end{array}$ & 24 & 5 & 6 & 28 & 26 & 38.1 & 3.9 & + & + & + \\
\hline 2 & $50 / \mathrm{M}$ & $\begin{array}{l}\text { Stricture \& coloanal } \\
\text { anastomosis }^{\mathrm{a}}\end{array}$ & $\begin{array}{l}\text { Resection of } \\
\text { gangrenous } \\
\text { rectal prolapse } 1 \\
\text { year back }\end{array}$ & 24 & 12 & ND & 20 & 25 & 26.2 & 9.2 & + & + & + \\
\hline 3 & 19/M & $\begin{array}{l}\text { Post RTA anal \& } \\
\text { urethral injury }\end{array}$ & Failed local repair & 24 & 4 & ND & 25 & 20 & 15.0 & 3.1 & + & + & + \\
\hline 4 & $38 / \mathrm{F}$ & Anal injury & Failed local repair & 24 & 5 & 13 & 23 & 16 & 12.6 & 5.5 & + & + & + \\
\hline 5 & $40 / \mathrm{F}$ & $\mathrm{APR}^{\mathrm{b}}$ & & 24 & 12 & & 17 & 18 & 22.4 & 10.5 & + & + & + \\
\hline 6 & $17 / \mathrm{F}$ & $\begin{array}{l}\text { Post RTA anal \& } \\
\text { urethral injury with } \\
\text { pelvic fracture }\end{array}$ & Failed local repair & 24 & 6 & 8 & 12 & 38 & 26.6 & 16.3 & + & + & + \\
\hline 7 & $7 / \mathrm{M}$ & $\begin{array}{l}\text { Post RTA anal } \\
\text { injury with } \\
\text { extensive fibrosis }\end{array}$ & - & 24 & 5 & 15 & 12 & $\mathrm{ND}$ & 46.5 & 10.4 & + & + & + \\
\hline 8 & $51 / \mathrm{M}$ & $\begin{array}{l}\text { Post RTA anal } \\
\text { injury }\end{array}$ & Failed local repair & 24 & 8 & 11 & 29 & 77 & 23.2 & 3.5 & + & + & + \\
\hline 9 & $18 / \mathrm{M}$ & $\begin{array}{l}\text { Post RTA anal, } \\
\text { urinary bladder } \\
\text { and urethral injury } \\
\text { with perianal } \\
\text { fibrosis }\end{array}$ & Failed local repair & 24 & 6 & 12 & 17 & 39 & 33.8 & 16.8 & + & + & + \\
\hline 10 & $11 / \mathrm{M}$ & $\begin{array}{l}\text { Post RTA anal } \\
\text { injury }\end{array}$ & - & 24 & 5 & 34 & 13 & 31 & 23.2 & 3.5 & + & + & + \\
\hline 11 & $30 / \mathrm{M}$ & Bullhorn anal injury & - & 24 & 6 & 44 & 27 & 74 & 33.8 & 16.8 & + & + & + \\
\hline 12 & $41 / \mathrm{F}$ & $\mathrm{APR}^{\mathrm{b}}$ & - & 24 & 7 & ND & 30 & 44 & 34.0 & 9.6 & + & + & + \\
\hline 13 & $52 / \mathrm{M}$ & $\mathrm{APR}^{\mathrm{b}}$ & - & 24 & 13 & ND & 20 & 23 & 39.1 & 16.3 & + & + & + \\
\hline 14 & $50 / \mathrm{M}$ & $\mathrm{APR}^{\mathrm{b}}$ & - & 24 & 14 & ND & 14 & 19 & 21.2 & 10.8 & + & + & + \\
\hline 15 & $35 / \mathrm{M}$ & $\mathrm{APR}^{\mathrm{b}}$ & - & 24 & 15 & ND & 36 & $\mathrm{ND}$ & 34.8 & 12.5 & + & + & + \\
\hline 16 & 19/M & $\begin{array}{l}\text { Unresectable rectal } \\
\text { cancer with } \\
\text { sigmoid colostomy }\end{array}$ & - & & & ND & 30 & ND & 50.1 & 21.6 & + & + & + \\
\hline 17 & $48 / \mathrm{M}$ & $\begin{array}{l}\text { Unresectable rectal } \\
\text { cancer with } \\
\text { sigmoid colostomy }\end{array}$ & - & & & ND & 28 & ND & 31.5 & 13.4 & + & + & + \\
\hline 18 & $19 / \mathrm{M}$ & $\begin{array}{c}\text { Post RTA anal \& } \\
\text { urethral injury }\end{array}$ & & & & ND & 38 & ND & 42.8 & 21.9 & + & + & + \\
\hline
\end{tabular}

${ }^{\mathrm{a}}$ Following resection of gangrenous rectal prolapsed, ${ }^{\mathrm{b}} \mathrm{APR}$ performed for rectal cancer.

Preop, preoperatively; Postop, postoperatively; Max, maximum; Min, minimum; F/U, follow-up; APV, antro-pyloric valve; ARM, anorectal malformation; RTA, road traffic accident; ND, not done.

Doppler velocities were classified as excellent $(>30 \mathrm{~cm} / \mathrm{sec})$, good $(20-30 \mathrm{~cm} / \mathrm{sec})$ and fair $(<20 \mathrm{~cm} / \mathrm{sec})$. 

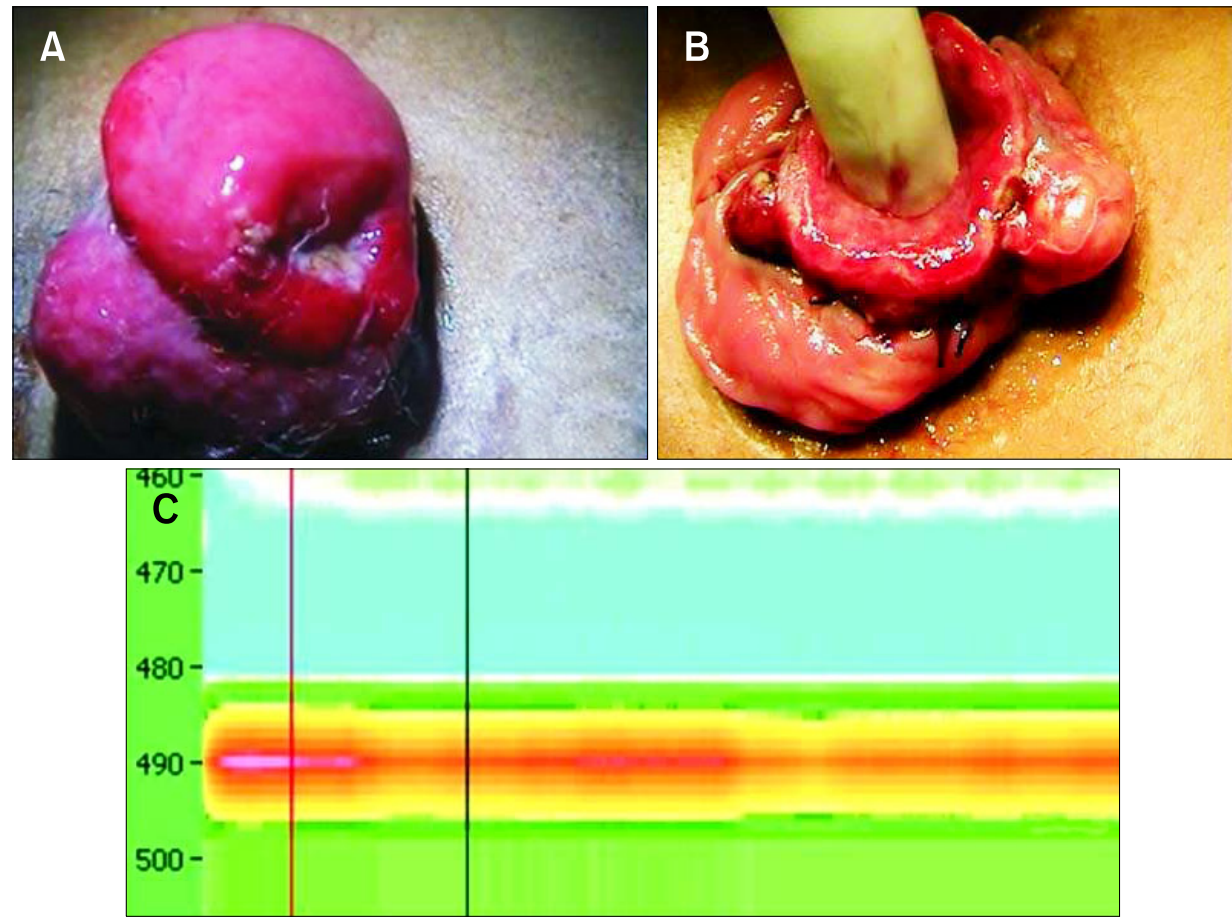

Figure 1. Operative photographs showing pyloric valve transposed on to the end sigmoid colostomy: graft has been taken up at ectopic position showing good vascularity (A) and finger inserted into the transposed pylorus: intermittent gripping sensation can be felt during prolonged insertion of the finger (B). (C) High-resolution manometry of the pyloric valve transposed on to the end colostomy. The yellow area is indicative of high pressure zone of the sphincter.
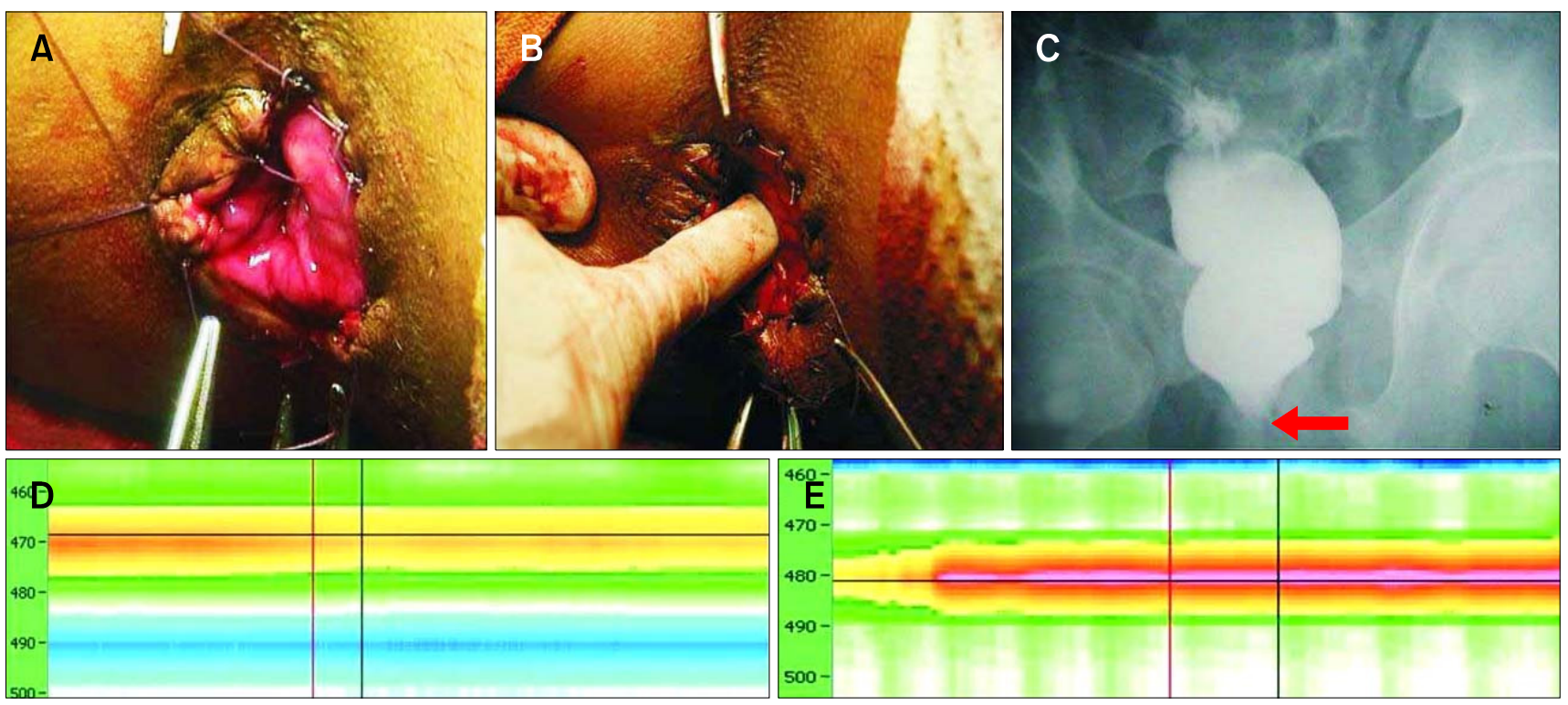

Figure 2. Pyloric valve transposed in the perineum showing distal (duodenal) end being anastomosed with the perianal skin (A), finger inserted in the transposed valve could feel a gripping sensation on prolonged insertion due to intermittent contraction of the valve (B). (C) Barium distal loopogram showing a distinct hold up at the site of pyloric valve (red arrow). Preoperative (D) and postoperative (E) high-resolution manometry tracing of the pyloric valve transposed in the perineum in a patient with anal injury. Yellow zone in pre-operative manometry indicate sphincter zone and post-operatively, sphincter pressure is increased (pink color). Reproduced from Goldsmith and Chandra ${ }^{5}$ with permission from Elsvier.

(Australia) (Fig. 1 and 2).

Preoperative manometry was performed in 8 patients (anorectal malformation: 1 and anal injury: 7) (Table). Post-op- erative manometry was performed after 2 weeks following APV transposition, and 4 weeks after colostomy closure (Table). 


\section{Fecal incontinence scoring}

Degree of fecal incontinence was clinically assessed by St Mark's fecal incontinence scoring system. ${ }^{8}$

\section{Distal loop barium retention studies}

To visualize the APV graft, barium studies were done through the distal loop of the diverting colostomy. Films were repeated after 15 minutes to observe retention of the barium proximal to the newly constructed sphincter (Fig. 2).

\section{Distal colonoscopic examination}

The pylorus was examined through the distal loop of diverting colostomy and also per-anally during colonoscopy to assess its activity (Fig. 3).

\section{Imaging}

\section{Perineal doppler studies}

This was performed pre-operatively in all patients to document the extent of anal sphincter damage and fibrosis. An ultrasound machine (GE voluson E8, GE, New York, USA) was used with high-resolution and short focus. Endo-cavity 3-dimen-

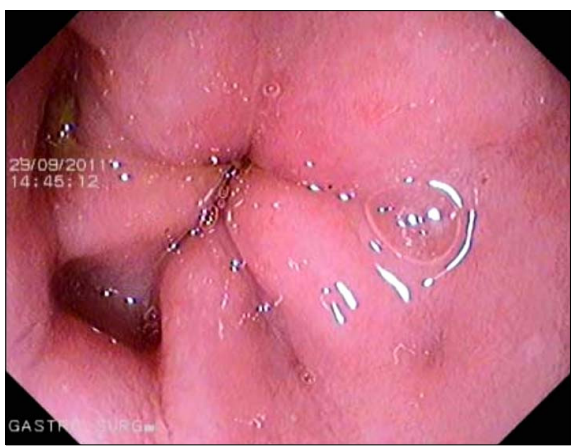

Figure 3. Transposed pyloric valve as seen during colonoscopic examination. Pyloric valve appeared closed with intermittent relaxation during prolonged examination. sional (3D) and 4D ultrasound transducers were used for evaluating the anal sphincter. Direct contact scanning technique was used with 10 and $12 \mathrm{MHz}$ transducers via both trans-perineal and endo-rectal routes. Multi-planer 3D real time construction of anal sphincter was carried out using real time 3D ultrasound probe. Color doppler imaging was done to evaluate the vascularization of the neo-graft. Arterial flow pattern was observed in the graft and flow velocities measured. The blood flow velocity was measured on spectral doppler tracing (Fig. 4).

\section{Magnetic resonance imaging}

Perianal MRI was performed pre-operatively in all patients with sphincter damage except where it was excised following an abdomino-perineal resection (APR) and was repeated post-operatively in each patient. Pelvic MRI was performed on a $1.5 \mathrm{~T}$ MR scanner (GE signa excite, Milwaukee, WI, USA) with a phase array coil (TORSO PA). Spin echo T1 and fast spin echo T2 sequences were performed in axial, coronal and sagittal planes. Scanning was performed from iliac crest to the ischial tu-

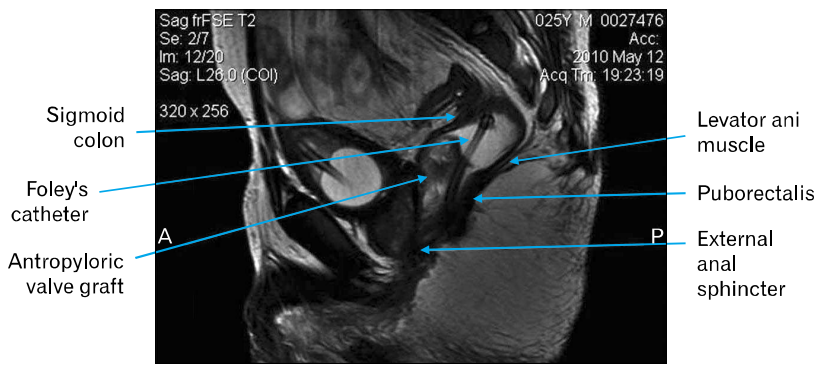

Figure 5. Parasagittal view of magnetic resonance imaging of the pelvis after antro-pyloric valve transposition showing well positioned pyloric valve (Foley's catheter has been inserted in the colon across the pylorus and slightly pulled out for better delineation and localization). Foley's catheter is also seen in urinary bladder as this patient also had urethral injury.
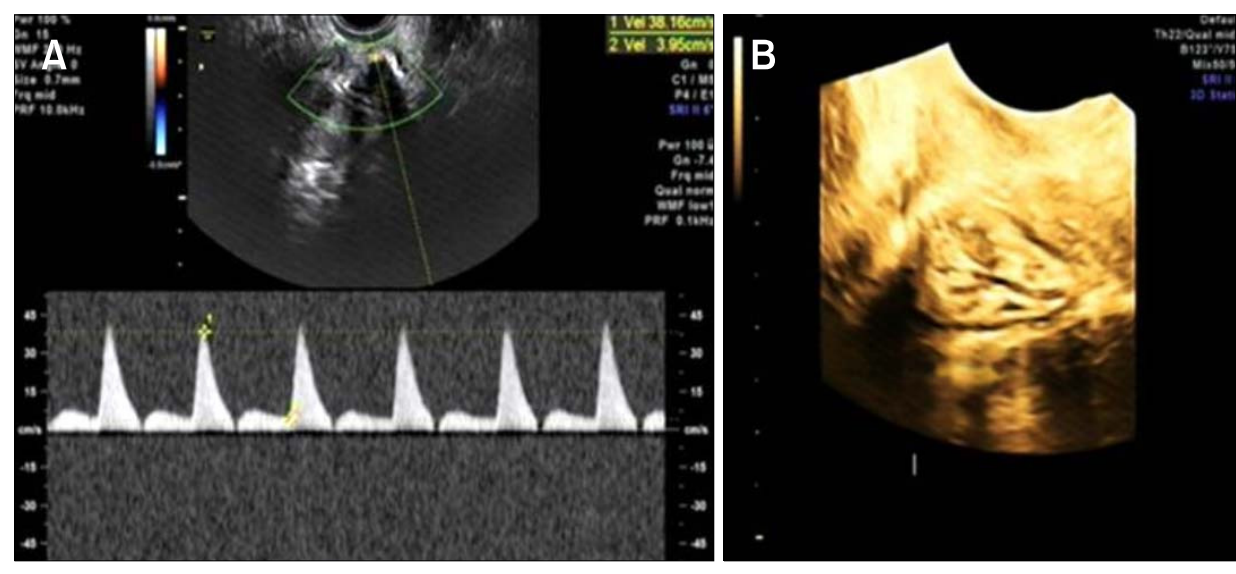

Figure 4. Transperineal ultrasonography with doppler study of the pyloric valve transposed in the perineum showing excellent vascular flow. 
berosity level with field of view of $16 \times 16 \mathrm{~cm}$ and slice thickness of $4 \mathrm{~mm}$ with $0.1 \mathrm{~mm}$ inter-slice gap (Fig. 5).

\section{Computed tomography angiography}

Celiac axis CT angiography was performed in all patients to assess the vascular flow to the neograft in perineum. A 64 slice scanner (Philips Brilliance 64, Best, Netherlands) was used; scanning was done from above the level of diaphragm to the ischial tuberosity. Bolus tracking was used with tracker placed on descending thoracic aorta. Slice thickness was $0.9 \mathrm{~mm}$ with increment of $0.5 \mathrm{~mm}$ and pitch of 1.015 with scan time of $4.56 \mathrm{se}-$ conds. Non-ionic contrast (Omnipaque, GE Healthcare, Shanghai, China) was intra-venously injected at a rate of $4.5-5 \mathrm{~mL} / \mathrm{sec}$ through an $18 \mathrm{G}$ ante-cubital venous access and pressure injector followed by $20 \mathrm{~mL}$ saline flush. Maximum intensity projection, volume intensity projections and volume rendering were done on Philips Brilliance Extended workstation for analysis (Fig. 6).

\section{Statistical Methods}

Continuous variables were expressed as median and range. Wilcoxon signed rank test was performed to compare the resting pressure during pre-operative, first and second post-operative follow-up in benign and malignant group. $P$-values of $<0.05$ were considered significant. All the analyses were performed using SPSS program, version 14.0 (SPSS Inc., Chicago, IL, USA).

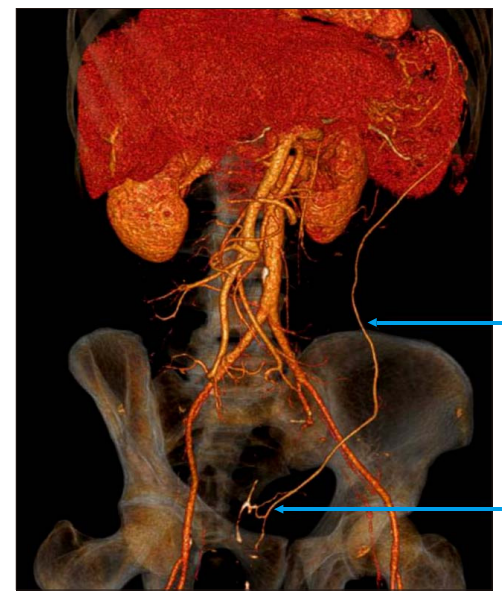

Gatroepiploic artery to transposed antro-pyloric valve graft

Terminal branches to antro-pyloric valve graft

Figure 6. Computed tomography angiography with 3-dimensional reconstruction showing left gastroepiploic pedicle as a supplying vessel to the transposed pyloric valve. Good vascularity is seen till pyloric valve.

\section{Results}

\section{Patients Demographics}

A total of 18 patients were included in the study (Table). There were 14 males and 4 females with a median age of 35 years (range 7-52). The most common indication of the APV transposition was post-traumatic end-stage anal incontinence.

APV was transposed on the sigmoid diverting colostomy in 2 patients with advanced cancer rectum. In another patient with traumatic injury to perineum, the APV was transposed on a pre-existing colostomy and later brought down to perineum in a staged manner.

APV was transposed in the perineum in patients with post-traumatic injury resulting in end-stage anal incontinence (n $=8)$, congenital absence of sphincter $(\mathrm{n}=1)$, strictured coloanal anastomosis following resection of gangrenous rectal prolapse ( $\mathrm{n}$ $=1$ ) and malignant lesions (ie, rectal cancer $[\mathrm{n}=5]$ ).

\section{Functional Evaluation}

\section{Antro-pyloric valve on colostomy}

The pylorus, transposed on the end-sigmoid colostomies, was found to be tonically contracted (Fig. 1). On inserting the index finger through the APV opening, a definite resistance and gripping sensation was felt (Fig. 1). With prolonged insertion, there was evidence of existence of a basal tone with intermittent contraction of the pyloric ring around the finger. The median resting manometric pressure in these patients was $30 \mathrm{mmHg}$ (range

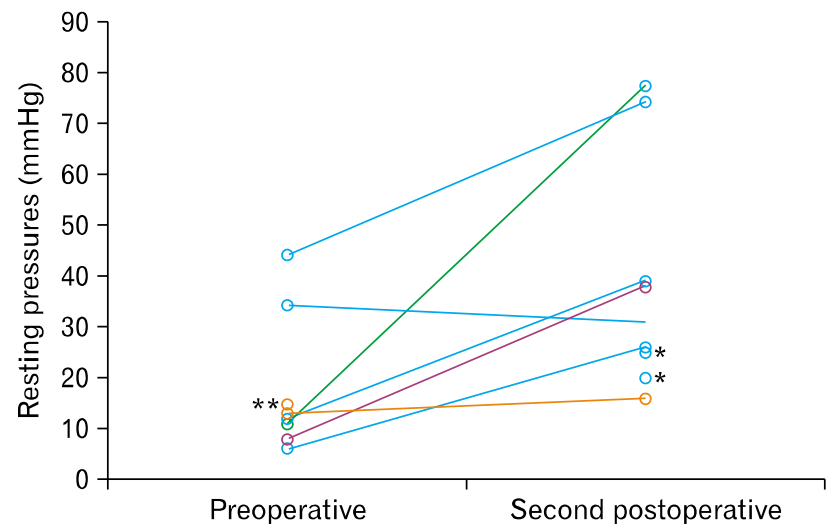

Figure 7. Wilcoxon signed rank test showing significant increase in resting pressures at second follow-up (as compared to preoperative pressures) in group 1 patients. ${ }^{*}$ Preoperative pressure measurement was not done, ${ }^{* *}$ Second postoperative pressure measurement was not done. 
28-38) (Fig. 1). The APV was well-visualized on abdominal wall and a CT angiogram showed the feeding gastroepiploic arcade adequately supplying the graft on top of the diverting colostomy.

\section{Antro-pyloric valve in perineum}

Digital examinations. Similar to APV on colostomy, inserted index finger felt a definite resistance and gripping sensation (Fig. 2). With prolonged insertion, there was evidence of existence of a basal tone with intermittent contraction of the pyloric ring around the finger.

High-resolution manometry. Overall, the median resting pressure was $20 \mathrm{mmHg}$ (range 12-36) and $26 \mathrm{mmHg}$ (range 16-77) on first and second postoperative studies, respectively (Table). In group 1 with benign indications, median resting pressure in perineum was $12.5 \mathrm{mmHg}$ (range 6-44) that increased to $21.5 \mathrm{mmHg}$ (range 12-29) $(P=0.481)$ and $31 \mathrm{mmHg}$ (range 16-77) $(P=0.034)$ on first and second follow-up, respectively (Fig. 7). In group 2 with APR, post-operative median pressures were $20 \mathrm{mmHg}$ (range 14-36) and $21 \mathrm{mmHg}$ (range 18-44) on first and second follow-up, respectively. Patients undergoing APR with APV transposition had assessment of anal sphincter pressure only post-operatively.

Distal loop barium retention studies. On barium distal loopogram, ectopically transposed APV appeared as a 'beaking' smooth impression with retention of barium proximal to the neo-sphincter (Fig. 2). Barium was retained in late films repeated after 15 minutes.

Distal colonoscopic examination. The APV was consistently found to be closed in its ectopic position. The pelvic pylorus remained closed and had to be thrust open by pushing the colonoscope under constant air insufflation through the diverted distal colostomy limb (Fig. 3).

\section{Evaluation by Imaging \\ Perineal doppler studies}

Color Doppler imaging showed good arterial inflow in the perineal APV graft. The median flow velocities were maximum $32.65 \mathrm{~cm} / \mathrm{sec}$ (range 12.6-50.12) and minimum $10.65 \mathrm{~cm} / \mathrm{sec}$ (range 3.1- 21.9) (Table and Fig. 4). Most patients (16/18) had good $(20-30 \mathrm{~cm} / \mathrm{sec}$ ) to excellent ( $>30 \mathrm{~cm} / \mathrm{sec}$ ) blood flow. Two patients had fair $(<20 \mathrm{~cm} / \mathrm{sec})$ blood flow.

\section{Magnetic resonance imaging}

The transposed APV was well-visualized in all patients on post-operative MRI study, which was performed in all the patients (Fig. 5).

\section{Celiac-computed tomography angiography}

This was carried out in all patients to observe the vascular flow to the APV in the perineum. The pedicle of the right and left gastroepiploic arteries supplying the APV in the perineum was well visualized on the CT angiography (Fig. 6).

\section{Discussion}

In the current study, we have shown that the human pylorus can be surgically transposed successfully over the colostomy or in the perineum and that it exerts a tonic pressure in the new location. In previous functional studies, ${ }^{1}$ APV has not been shown to possess definite sphincteric characteristics. While pyloric high pressure zone could not be demonstrated in these early studies using balloons as pressure sensors, ${ }^{1}$ later studies using perfusion catheter systems did demonstrate the presence of such high pressure zone in the pylorus both in animals and in humans. ${ }^{9}$ In these later reports, Fischer and Cohen ${ }^{9}$ suggested that the pyloric high pressure zone was due to greater sensitivity of perfused catheters. Subsequently, Mcshane et $\mathrm{al}^{10}$ found no definite evidence of pressure barrier at the pylorus under basal conditions, after stimulation with $\mathrm{HCl}$ and with postural changes in different groups of patients. Gaffney et $\mathrm{al}^{2}$ have also reported the absence of a tonic sphincter at the human pylorus.

In vivo manometric assessment of the pylorus is difficult, primarily due to its constant movement during peristalsis. Since the musculature of the distal pyloric muscle loop is asymmetrical, radial asymmetry of the pyloric pressure profile may also contribute to discordant results in various studies. ${ }^{11,12}$ These conflicting findings on the pyloric motor function may also be attributed to the use of techniques that are poorly suited to pyloric manometry. More recently Desipio and Friedenberg, ${ }^{13}$ using high resolution solid state manometry, concluded that the pylorus did function as a classic sphincter with an intrinsic basal tone.

Factors controlling the function of the APV remain unknown. In fact, even the mechanisms of APV functions in its normal position between the stomach and the duodenum are unclear. It has been reported that certain hormones, such as cholecystokinin, or acid infusion in the duodenum can increase pyloric valve tone. ${ }^{14}$ Although physiological investigations in studies on human pylorus showed conflicting results, several observations suggest a definite sphincteric action. ${ }^{9,13}$ It has been observed that the circular pyloric muscle has a characteristic dose response. In vitro studies on the human pylorus have shown a definite dose-dependent contraction to gastrointestinal hormones 
as compared to the adjacent gastric antral musculature. ${ }^{15}$ In patients with gastric ulcers, increased duodenogastric reflux due to abnormal pyloric sphincteric action has been implicated as one of the mechanisms of pathogenesis. ${ }^{16}$ Pyloric pressure also increases in patients with diabetic gastroparesis and decreases after botulinum toxin injection. ${ }^{17}$

It has been shown that the basal pyloric tonic and phasic contractions persist even after application of tetrodotoxin. Tetrodotoxin also increases the spontaneous activity, suggesting a tonically active inhibitory neural innervation at the gastroduodenal junction. Thus, this inhibitory pathway in association with vagal inhibitory fibers may contribute to the tonic inhibitory innervation at the pylorus. ${ }^{1,18}$

The work on transposition of gastroduodenal pylorus as a sphincter to the end of an ileostomy was first reported in dogs by Ger et al. ${ }^{19}$ The results indicated that the gastroduodenal pylorus acted as a functioning sphincter, which delayed the passage of ileal contents with higher mean pressures. ${ }^{7}$ Subsequently, in another experimental study in cats, Goldsmith and Steward ${ }^{20}$ showed the feasibility and effectiveness of pyloric transposition after APR. Over the years, several other investigators have developed this technique for fecal control and auto-transplantation of the APV has been successfully accomplished in animals with sphincter like mechanism. In a major study, Erdogan et $\mathrm{al}^{21}$ using contrast defecography showed hold up of contrast at the transplanted pylorus in the perineum with reflux into proximal sigmoid colon in pigs. Manometry also showed pyloric contraction in the perineum with rise in its pressure. APV has also been used for preventing ileostomy complications in another canine study by Toubanakis et al. ${ }^{22}$ Auto-transplantation of the pyloric sphincter at terminal colostomies has also been performed in dogs. ${ }^{23}$ Although the transposed pyloric sphincter alone was not sufficient to control continence in this study, yet the resting manometric pressures were higher in the transposed group.

We have shown earlier the feasibility of perineal transposition of the pylorus in humans. ${ }^{5}$ The transposed antro-pylorus in perineum is physically viable as evidenced by digital examination and imaging studies including CT and MRI scans (Fig. 5 and 6). CT angiography and Doppler flow studies showed good vascular flow in the perineally transposed APV graft (Fig. 4 and 6). The APV in the perineum behaved as a functional tonic sphincter with anal manometry demonstrating a definite high pressure zone and significant retention of barium proximal to the transposed valve (Fig. 2).

All the previous studies in human have examined the APV in its natural in vivo position with intact gastroduodenal continuity. The pylorus in this position is difficult to access. However, ectopically placed pylorus (as in our series of patients) is relatively fixed and readily approachable. The transposition of the pylorus to an ectopic position could abolish the usual inhibitory control at the gastro-duodenal junction, which leads to a tonically contracted pylorus, an observation noted in most of our patients. The ectopically placed pylorus at the colostomy site was found to be well contracted with resistance to the invaginating index finger.

Of interest is the fact that in several of our patients, a prolonged insertion of finger in the newly positioned APV in the anal region resulted in a firm phasic contraction of APV with a basal tone around the inserted finger (Fig. 2). This suggests that the tactile stimulation of the APV might be responsible for its contraction in this position. The APV was consistently found to be closed in its ectopic position unlike its normal position in stomach where it is often open on upper gastrointestinal endoscopy. Barium retention studies have also shown adequate hold up of contrast in late films proximal to the transposed neo-pylorus in the perineum (Fig. 2).

Non-significant improvement in anal pressure was noted at first follow-up while pressures increased significantly at second follow-up. In-fact, 2 patients (No.10 and 11) had pressures lower than pre-operative values at first follow-up but had high pressures on second follow-up. This observation is also reflected in overall analysis as significant improvement in pressure was observed only at second follow-up, not at first follow-up. It is difficult to explain this observation. It might be related to better postoperative recovery and healing of transposed valve. Incontinence scoring was performed at second follow-up after colostomy closure. The scores correlated better with second pressure measurements than first.

Our results may have limitation due to small sample size. Nevertheless, our data, using multiple methodologies, points to a distinct sphincter action of the pylorus. These results may need to be validated in a larger study. Our unique set of patients in whom the pylorus was removed from the gastro-duodenal continuity provided us with the rare opportunity of examining the sphincter-like properties of the pylous, which had not been examined hitherto in this position.

We conclude that when removed from the gastroduodenal continuity, the pylorus functions as a tonic sphincter. This observation forms the basis of using an isolated pylorus in anal sphincteric reconstruction for the augmentation or replacement of the damaged sphincter. ${ }^{5}$ 


\section{Acknowledgements}

The authors thank Dr. Animesh Chandra, Science Writer, Institute for Translational Sciences, University of Texas Medical Branch, Galveston, for editing assistance. Dr. David Rew, Professor, University of Southhampton, UK for reviewing the manuscript.

\section{References}

1. Brink BM, Schlegel JF, Code CF. The pressure profile of the gastroduodenal junctional zone in dogs. Gut 1965;6:163-171.

2. Gaffney PR, Gleeson DJ, Hall JW, Brady MP. The Manometric findings at human pylorus: the evidence against the presence of a tonic sphincter. Scand J Gastroenterol 1987;22:525-532.

3. Winians CS. The fickle pylorus. Gastroenterology 1976;70:622-623.

4. Kang HW, Jung HK, Kwon KJ, et al. Prevalence and predictive factors of fecal incontinence. J Neurogastroenterol Motil 2012;18:8693.

5. Goldsmith HS, Chandra A. Pyloric valve transposition as substitute for a colostomy in humans: a preliminary report. Am J Surg 2011; 202:409-416.

6. Azpiroz F, Enck P, Whitehead WE. Anorectal functional testing: review of a collective experience. Am J Gastroenterol 2002;97:232240.

7. Jorge JM, Wexner SD. A practical guide to basic anorectal physiology investigations. Contemp Surg 1993;43:214-224.

8. Vaizey CJ, Carapeti E, Cahill JA, Kamm MA. Prospective comparison of faecal incontinence grading systems. Gut 1999;44:77-80.

9. Fisher R, Cohen S. Physiological characteristics of the human pyloric sphincter. Gastroenterology 1973;64:67-75.

10. McShan AJ, O'Morain C, Lennon JR, Coakley JB, Alton BG. Atraumatic non-distorting pyloric sphincter pressure studies. Gut
1980;21:826-828.

11. Schulze-Delrieu K, Ehrlein HJ, Blum AL. Mechanics of the pylorus. In: Akkermans LMA, Johnson AG, Read NW, eds. Gastric and gastroduodenal motility. New York: Praeger 1984;87-102.

12. Torgersen J. The muscular build and movements of the stomach and duodenal bulb. Acta Radiol 1942;45:1-191.

13. Desipio J, Friedenberg FK, Korimilli A, Richter JE, Parkman HP, Fisher RS. High-resolution solid-state manometry of the antroduodenal region. Neurogastroenterol Motil 2007;19:188-195.

14. Isenberg JI, Csendes A. Effect of octapeptide of cholecystokinin on canine pyloric pressure. Am J Physiol 1972;22:428-431.

15. Lipshutz W, Cohen S. Interaction of gastrin 1 and secretin on gastrointestinal circular muscle. Am J Physiol 1972;222:775-781.

16. Rhodes J, Barnardo DE, Philips SF, Rovelstad RA, Hofmann AF. Increased reflux of bile into the stomach in patients with gastric ulcer. Gastroenterology 1969;57:241-252.

17. Lacy BE, Crowell MD, Schettler-Duncan A, Mathis C, Pasricha PJ. The treatment of diabetic gastroparesis with botulinum toxin injection of the pylorus. Diabetes Care 2004;27:2341-2347.

18. Anuras S, Cooke AR, Christensen J. An inhibitory innervation at the gastroduodenal junction. J Clin Invest 1974;54:529-535.

19. Ger R, Condrea H, Raskin N, Addei K. Preliminary report. The transposition of a living sphincter. J Surg Res 1982;33:69-73.

20. Goldsmith HS, Steward E. Fecal continence after abdominoperineal resection using the pedicled pyloric valve - an experimental study. Clin Oncol 1982;8:313-317.

21. Erdogan E, Rode H, Hickman R, Cywes S. Transposition of the antropylorus for anal incontinence - an experimental model in the pig. $\mathrm{J}$ Pediatr Surg 1995;30:795-800.

22. Toubanakis G, Peveretos P, Toubanakis C, Golematis BC. Use of the pylorus for preventing ileostomy complications. An experimental canine study. Dis Colon Rectum 1996;39:266-269.

23. Centeno Neto AA, Veyrac M, Briand D, Spiliotis J, Saint-Aubert B, Joyeux $\mathrm{H}$. Autotransplantation of the pylorus sphincter at the terminal abdominal colostomy. Experimental study in dogs. Dis Colon Rectum 1991;34:874-879. 